\section{AIRAPT}

\section{[Continued from Page 5]}

include particularly illuminating aspects such as especially accurate or novel experiments or theories, states like mesophases that cannot be studied at higher pressures, and the like. Topics will include freezing and glass transitions, equilibrium properties, structural properties,physical and chemical relaxation processes, geophysical and geochemical applications, technological applications, etc.

The program is organized by cochairmen E. Whalley and J. Jonas. Write to:

E. Whalley

Division of Chemistry

National Research Council

Ottawa, K1A OR9

Canada

\section{Engineering and Safety-}

The High Pressure Engineering and Safety symposium is the Third International High Pressure Engineering Conference, the successor

\title{
MRS AFFILIATES WITH A I P
}

The Materials Research Society has become an Affiliated Society of the American Institute of Physics. Formal affiliation was unanimously approved by the MRS Council in March.

The principal immediate benefit that will accrue to MRS members is that they will qualify to receive the journals of Member and Affiliated Societies of the AIP at member rates. Longer term, the Society intends to improve its internal operations and broaden the range of professional benefits it is able to offer its members through AIP affiliation. The most widely known of AIP's publications is Physics Today.

The American Institute of Physics was established as a non-profit organization in 1931 for the purpose of assisting societies with an interest in physics in promoting the advancement and diffusion of the science. In general it sought to leave to constituent societies the responsibility for holding scientific meetings and offered to to meetings held in London in 1967 and Brighton in 1975. Unlike the other symposia of the present conference, which deal with the physics and chemistry of materials subjected to high pressures, this meeting will be concerned with the engineering aspects of generating, controlling, containing and using high pressures. For the purposes of this symposium, "high" pressure is considered as pressure exceeding about one kilobar $(15,000$ psi).

Sessions are planned in the general areas of:

Design, including closures, seals and the use of residual stresses.

Materials, including fatigue, fracture, environmental effects and superhard materials.

Applications, including hydrostatic extrusion and compaction and jet cutting.

Safety, including protection barricades, pressure release devices and nondestructive inspection.

The program, which will include both invited and contributed papers and utilize both lecture and poster

presentation formats, is being organized by a program committee co-chaired by D.J. Burns and D.P. Kendall. Write to: D.J. Burns

Department of Mechanical Engineering University of Waterloo

Waterloo, Ontario

Canada

Fees

The registration fee will be US $\$ 125$, which will include the social program, banquet and published proceedings. There may be a small additional registration fee for companions to cover the cost of the social program. There may be available small grants toward the expenses of students whose expenses are not met from other funds. Applications for student grants should be sent to:

Clarke G. Homan

Physics Department

State University of New York

Albany, NY 12222

\section{BRIEFS}

PROCEEDINGS VOLUMES, which have and continue to result from several of the Materials Research Society's topical symposia, as well as from MRS-sponsored topical conferences, have been registered as a series as an irregular serial publication. Each volume will, therefore, be assigned, in addition to its own international standard book number (ISBN), a common international standard serial number (ISSN). The change permits the various abstracting services to include the MRS series in their coverage.

Authors citing work appearing in the series are advised the appropriate abbreviated form should read:

Mat. Res. Soc. Symp. Proc. Vol., Page (Year).

Source: MRS Publications Committee Aeronautics, American Society for Metals, Electron Microscopy Society of America, Geological Society of America, Instrument Society of America and the Society for Applied Spectroscopy.

Affiliation with AIPiswithout cost to the Society or its members.
HARRY C. GATOS, professor of electronic materials and molecular engineering, Massachusetts Institute of Technology - and a founder of the Materials Research Society - has been elected a member of the National Academy of Engineering. 